\title{
Development of an ergonomics device for maintenance of hydraulic generators of Tucuruí hydropower plant
}

Batista, I.C. ${ }^{\text {a }}{ }^{*}$, Gomes, G.J.C ${ }^{\text {a }}$, Teles, C.S ${ }^{\text {a }}$, Oliveira, P.F. ${ }^{\text {, }}$, Santos, R. M. ${ }^{\text {b }}$, Sassi, A. C. ${ }^{c}$ Sá, B. ${ }^{\text {c }}$, B. $\mathrm{V}^{\mathrm{d}}$ and. Pardauil ,A. $\mathrm{A}^{e}$

${ }^{a}$ Mechanics Maintenance Area, Eletrobras Eletronorte, Vila Permanente, Tucuruí, Pará, Brazil

${ }^{\mathrm{e}}$ Health Pillar, Eletrobras Eletronorte, Vila Permanente, Tucuruí, Pará, Brazil

${ }^{f}$ Strategic Management Committee, Eletrobras Eletronorte, Tucuruí, Pará, Brazil

${ }^{\mathrm{f}}$ hHydraulic Generation Superintendent, Eletrobras Eletronorte,Vila Permanente, Tucurui, Pará, Brazil

\begin{abstract}
This paper aims to present an ergonomic device to assist in the maintenance of the units of Tucuruí Hydropower Plant. The development of this ergonomic device made possible to reduce maintenance time, reduce losses caused by billing, improve performance and reduce the physical strain for labors during the execution of services.
\end{abstract}

Keywords: Device, maintenance, ergonomics 


\section{Introduction}

Tucuruí Hydropower Plant is the largest hydroelectric plant in Brazilian territory $(8370 \mathrm{MW})$, as the Itaipu plant is binational. It is located on the Tocantins River in the town of Tucuruí, about $400 \mathrm{~km}$ from Belém, in Pará State. It was built to generate electricity and to make a navigable a stretch of the river full of rapids, overcoming them by means of a lock chamber.

With the globalization of market competition became fiercer, requiring companies a world-class performance. Given this need, companies have been adapting to the standards of quality, so it becomes necessary to do the maintenance at specific periods, thus avoiding undue costs with corrective maintenance. Such things confirm the importance of implementation of a methodology with focus on preventive maintenance, exactly what is approached in TPM and ergonomics science.

The purpose of this paper is to present the development of an ergonomic device constructed inside Tucuruí plant in order to held generating units maintenances during a shorter time and reduce the physical exertion made by employees during the execution of services.

The text is made up of a section that presents the theoretical framework about the maintenance history, with application of the Total Productive Maintenance methodology. Next are the methodology and development stages of the ergonomic device and finally, it presents final considerations for the work.

\section{Maintenance history}

According to Monchy, the term "maintenance" has its origin in military vocabulary whose meaning was "keeping the military personnel and the material at a constant level in combat units". Clearly, the units that interest us here are the production units, and the combat is primarily economic. The appearance of the term "maintenance" in the industry occurred around 1950 in the United States of America. In France, this term overlays progressively the word "conservation" [1].

The industries need urgent technical and administrative changes in all sectors to ensure their productivity. Maintenance has to be modern and efficient, keeping up with the rhythm of the whole technological development process, and before becoming one more obstacle to the means of production it must always seek the best solutions, seeking to always seek the best solutions, seeking to make the set more agile and dynamic, because its role is to support the production.

More broadly, the term maintenance encompasses the concepts of prevention (keeping) and fix (restore) [2]. Monchy [1] also comments on the blank left by most definitions when they make no reference to the economic aspect involved in making an efficient maintenance, which should ensure that its activities would lead to an overall optimized cost.

According to Nakajima [3], the evolution of the maintenance system in Japan was done in four phases: Corrective Maintenance, Preventive Maintenance, Production System Maintenance and TPM.

TPM also includes Predictive Maintenance techniques, ie, the use of tools that enable preliminary diagnosis of machinery and equipment.

TPM focuses on reducing costs with equipment's life cycle, combining preventive maintenance with sustainable improvements and preventive maintenance project. TPM yields autonomous maintenance of a production that attempts to optimize the operator's skill and knowledge of own working equipment to maximize its operating efficiency.

In consonance with the definition of TPM, each letter has its own meaning as follows:

- The letter "T" means "TOTAL". Total in the sense of overall efficiency, also in the sense of total life cycle of the production system and in the sense of the totality of departments and participation;

- The letter "P" means "PRODUCTIVE." The quest of the system of production to reach the maximum efficiency, achieving "zero accidents, zero defects and zero breakdowns/failure", that is to say, the elimination of all types of loss until reaching the zero;

- The letter "M" means "MAINTENANCE". Maintenance in the broad sense, which has as its object the total life cycle of the production system, additionally means the maintenance that that has as object the production system of single process, the factory and the sales system. The following item will address the implementation of ergonomics principles in the company.

It is important to remind the fact the TPM methodology is used in Tucuruí plant since 1999 and it has been contributing significantly to the development of the ergonomic process in the company. 


\subsection{Ergonomics program in Tucuruí plant}

After the implementation of the TPM methodology in Tucuruí plant, the organization of the Ergonomics Program had its start in 2001, introducing the development of various actions, such as: analysis of work from an ergonomic point, awareness of the workforce, changes in the workspaces, and studies for the development of ergonomic devices.

In 2006, the Ergonomics Committee was structured, comprising representatives from all areas of Tucuruí plant, whose goal is the early identification of ergonomic non-conformities, that is, potential causes of musculoskeletal and psychological injuries in the workplace or while using tools or finding issues of working methods.

The Ergonomics Committee considered that the maintenance process demands great physical exertion and requires a person to put him/herself in awkward postures due to the difficulty of entering the place on its own, without forgetting the weight of tools; thereupon, in accordance with the direction of the committee it was defined the adoption of the tool developed by Suzanne Rodgers (Suzanne Rodgers' Analysis adapted by Santos) to define the criticality of ergonomic workstations.

Given the difficulties encountered during the execution of maintenance, even the personnel who carry out the maintenances proposed changes and innovations with support of the company's ergonomist. It is noteworthy that the ergonomist always leads the studies from physiological, psychological and humane cognition variables following criteria that must always focus on the human being.

For this, we developed an ergonomic device to assist maintenances in units of the Tucuruí plant, such to reduce the physical exertion of employees at work, reduced maintenance time and consequently reduce machine downtime which causes loss the company's profit.

\section{Methodological aspects}

The research strategy adopted in this paper is the case study. According to Godoy [4], the case study has become the preferred strategy when researchers want to answer the questions "how" and "why" certain phenomena occur.

In reference to the nature of the studied variables, the research is characterized as qualitative, since the case studies are based on qualitative evidences. This occurs because such research involves obtaining descriptive data about certain places, people or interactive processes; through direct contact of the researcher with the studied situation, trying to understand the phenomena from the perspective of the subject [4]. In this scenario, the case study was conducted at the Tucuruí Hydropower Plant to the development of ergonomic device to be used in the maintenance of generating units.

\section{Development of the improvement (Kaizen)}

The Tucuruí plant has 25 generating units, those are scheduled for review in its various systems every five years, an average of five units per year. The braking system, for which this tool was developed, is one of the most important systems of the generator, because it stops the machine not only in normal operation, but in emergency situations.

The maintenance of this system consists in removing the brake actuator (Figure 1) from its base for inspection and replacement of the pads (brake plates) and repair of the actuator's piston, this activity was performed using tools such as hand chisel, cargo slings and steel cables. Before the development of ergonomic device was only possible to remove the piece to the point of $0.6 \mathrm{~m}$ high (Figure 1). This movement required to be on squatting position or to lie on the sides of the body and even high physical exertion in a condition of intense thermal discomfort. Under these conditions, it took approximately 26 days to perform maintenance, resulting in a loss of power generation of $218,400 \mathrm{MW} / \mathrm{h}$, which represents a loss of revenue of $\$ 1,193,010.00$.

Faced with the need to eliminate or minimize the ergonomic risk goals were outlined to improve working conditions in order to: reduce the exposure time of workers on site, improve posture during the execution of maintenance tasks, reduce the number of man*hours spent in the activity and increasing the productivity of electric power generation.

The implementation of ergonomic device had an estimated investment of $\$ 625.00$ in materials. It should be noted that the device was developed with reused materials, based on the concept of the $3 \mathrm{Rs}$ (reduce, reuse and recycle) [5]. In the initial planning it was set a $50 \%$ gain in time for this type of activity, after the first tests it was noticed that the time spent would be less than the value in the plans. The steps in the development of the improvement will be detailed below. 


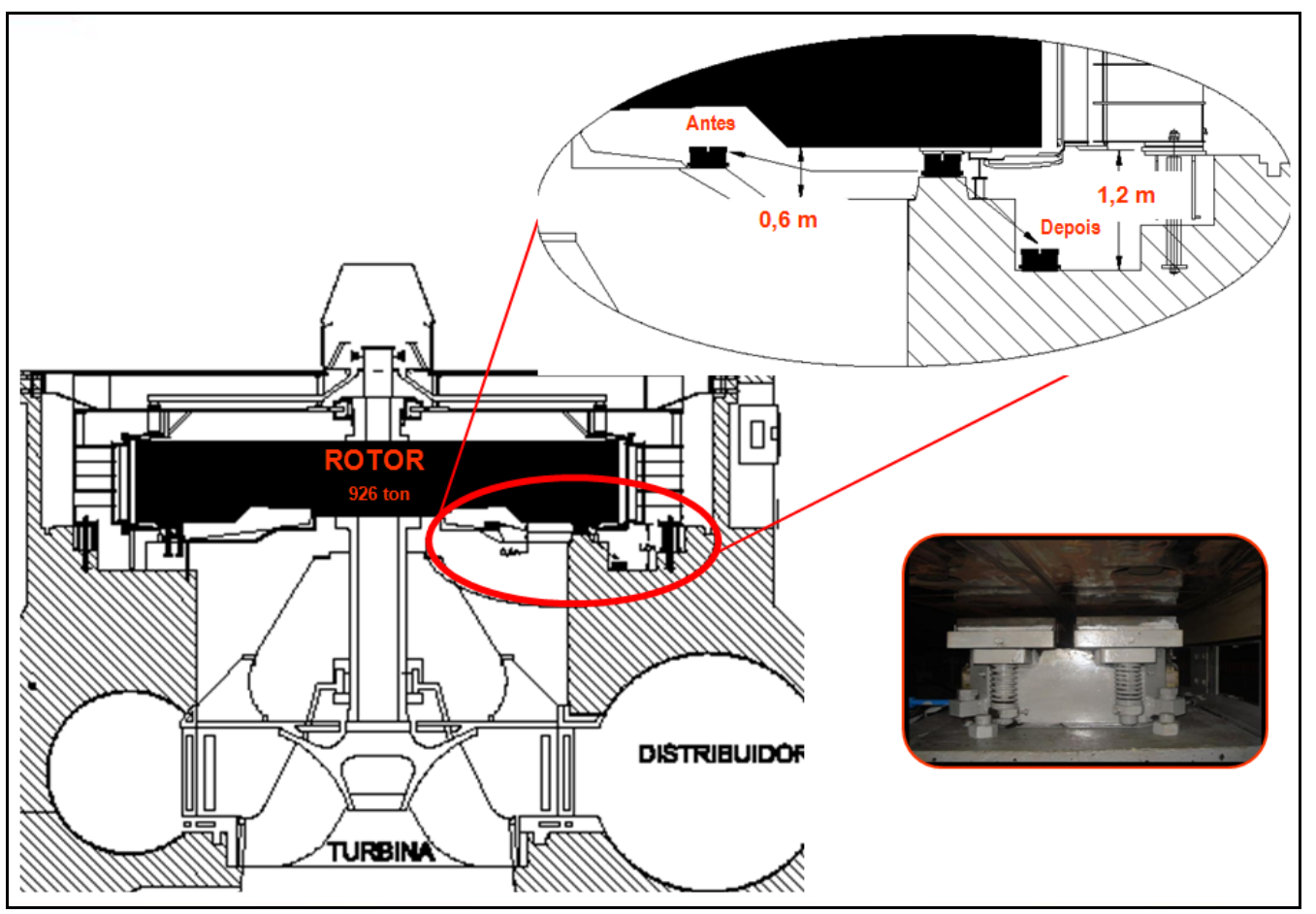

FIGURE 1 - Cross section of hydraulic generator

\subsection{Formatting the idea}

After finding the difficulties in carrying out this activity, the maintenance team and the company's ergonomics committee sought after a proposal for a tool that could assist in carrying out the maintenance activity aiming at the reduction of the physical exer- tion required from employees, consequently providing greater agility in task execution, reduce the risk of accidents and decrease the time of exposure to the anti-ergonomic conditions of the site. Figure 2 shows how the braking system maintenance was done before the development of the ergonomic device.

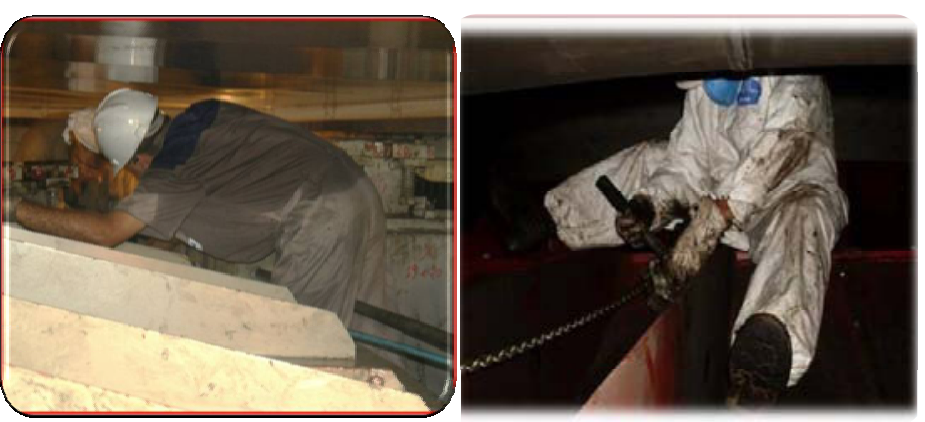

Figure 2 - Braking system maintenance before the ergonomic device

\subsection{Conducting on-site measurements}

The adopted tool for defining the ergonomic criticality - Suzanne Rodgers - works on after the evalu- ation of a body segment, its exertion in implementing the activity as well as the amount of this exertion that is present within a work cycle; due to the presented fact (number of repetitions of the activity/exertion versus short work cycles) [6]. The main- 
ty/exertion versus short work cycles) [6]. The maintenance service before the device was made ranked very high in criticality, as can be seen in Figure 3. In addition, for the development of ergonomic device, measurements and verification of environmental conditions were performed (measurement of physi$\mathrm{cal} /$ structural arrangement) then it was observed and recorded the anthropometric profile of workers.

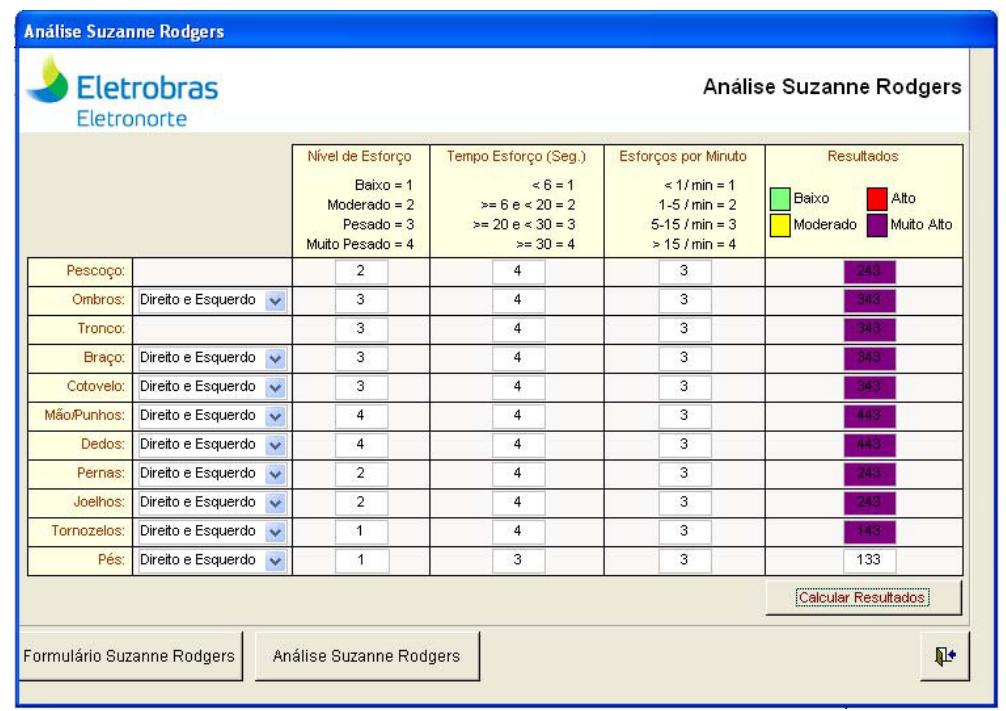

Figure 3 - Suzanne Rodgers' analysis adapted by Santos

\subsection{Tool design}

The measurements carried out on site posed as the base for the development of a prototype of the ergonomic device created by the team of technicians.
To meet maintenance needs it has been developed a tool that reduces the effort of the worker and it should be easy to handle during the task.

Figure 4 shows the ergonomic device sketch.
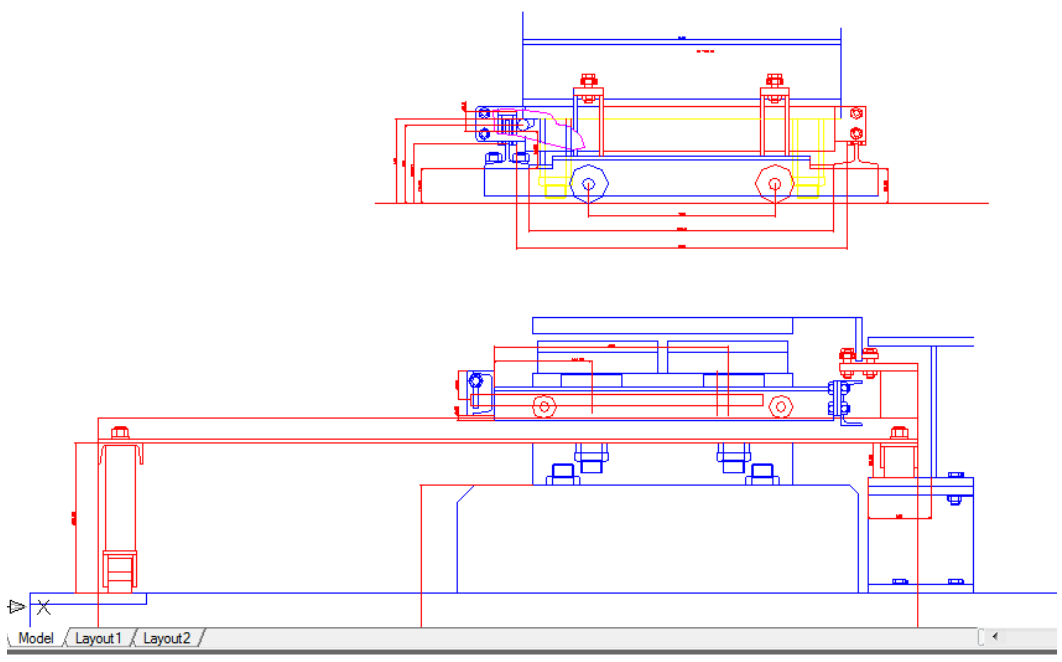

Figure 4 - Sketch of the device in operation

4.4. Development of the Tool 
Figure 5 shows the ergonomic device for the braking system. The mechanical device consists of:

- Main Car - this performs the longitudinal or lateral movements;

- Transversal Car - mounted on the main car, it does the radial movement of the machine;
- Lifting System - mounted on the transversal car, it does the lifting job of the part;

- Elevator - removes the part from the transversal car and moves it to the floor and provides the return of this part for reassembly.

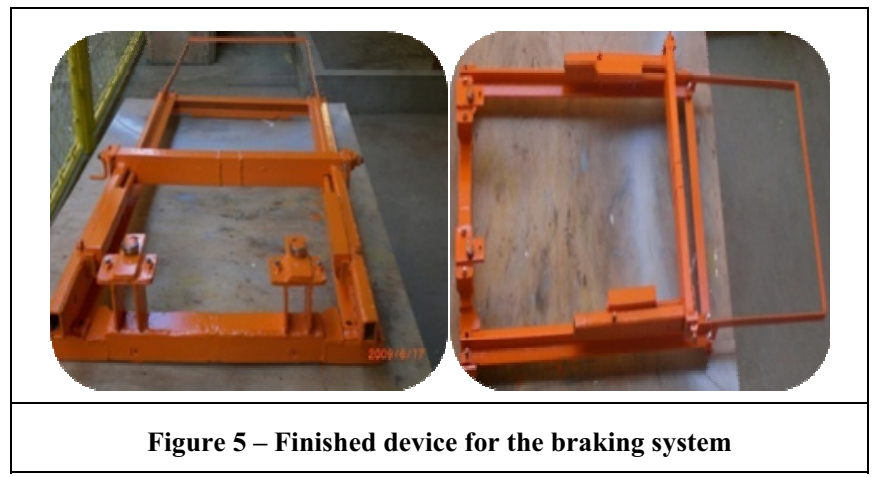

\subsection{Tests}

Three tests were performed during a review of the machine in a real working condition and have been detected at this stage a few necessary adjustments, we may cite for example, the height adjustment of the main car, since there are differences between the original machine design and the physical measurements of the machine, aside that there was a need for modification of fixed parts of the device for mobile ones for facilitating the handling of it. Figure 6 shows the images of the tests performed in a real condition during maintenance.

\subsection{Simulation after adjustments and finishing}

This device loaded can be operated by one person, using only one hand, applying a small force.

Figure 7 shows the ergonomic device.

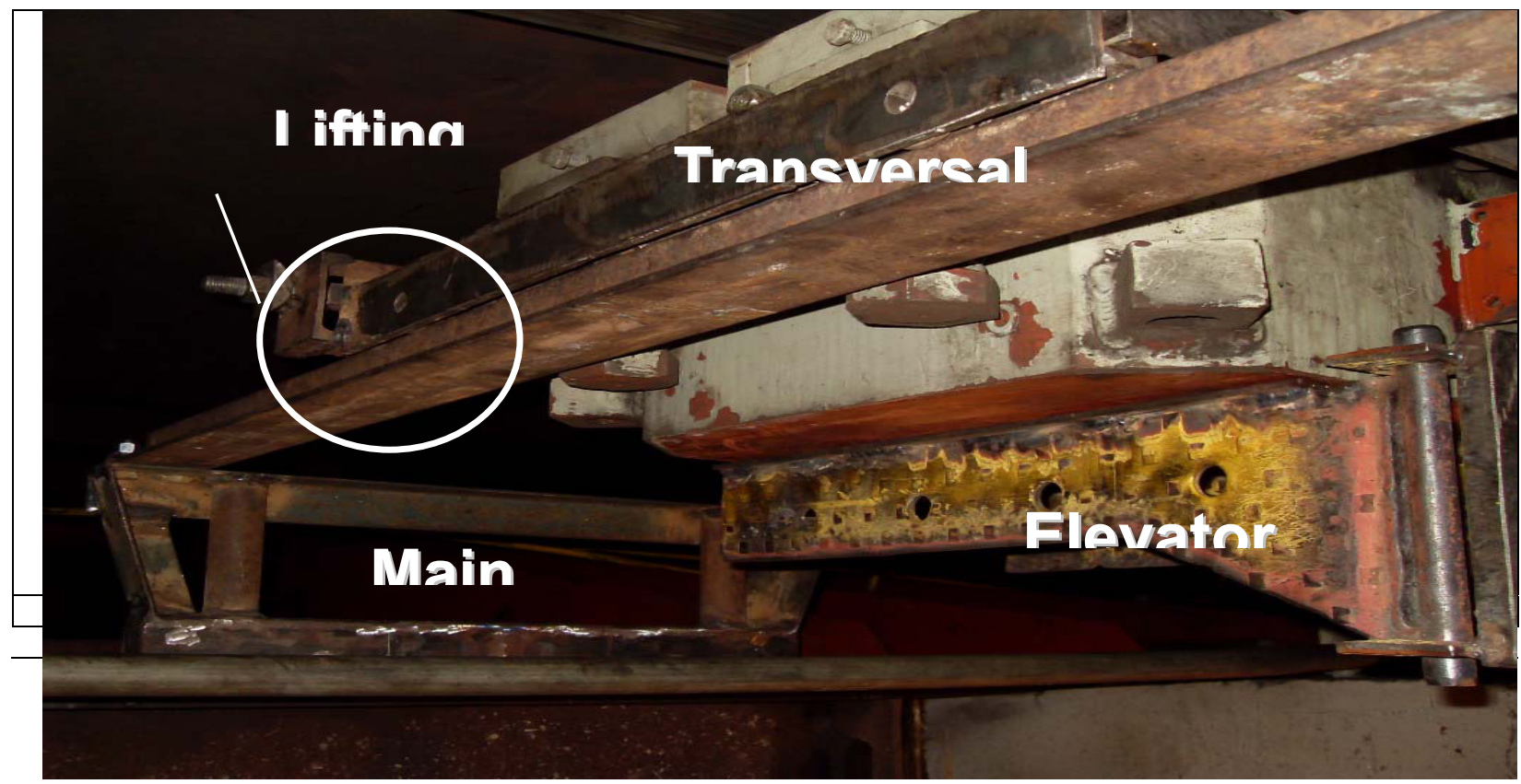




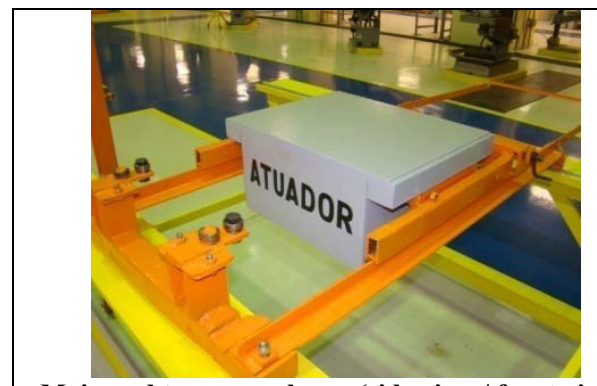

Main and transversal cars (side view / front view / top view)

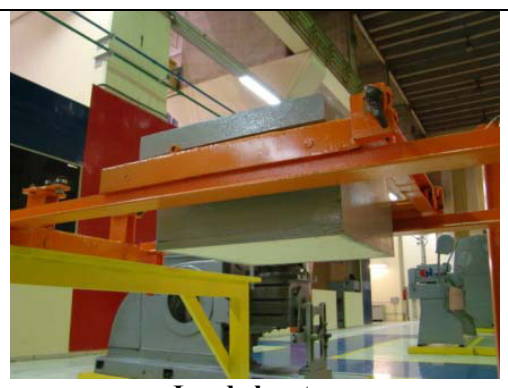

Load elevator

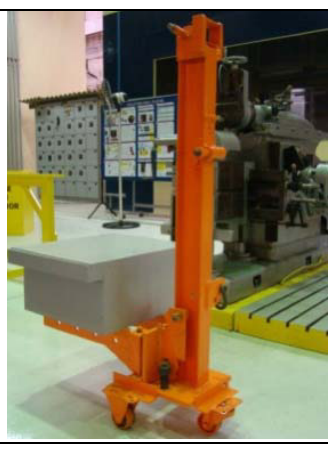

Figura 7 - Ergonomic Device

\section{Results}

The results were significant for the improvement of the production process, which saw after the deployment of the tool a reduction of 16 days in the time of maintenance. There was also a $62 \%$ reduction in the amount of man*hours necessary and another reduction from $218,400 \mathrm{MW} / \mathrm{h}$ for 84,000 $\mathrm{MW} / \mathrm{h}$ in losses in electricity generation, which represents a savings of $\$ 721,660.00$ for the company.
The results were positive for the health of the worker, who came to do his maintenance job from the highest point of the site $(1.20 \mathrm{~m})$, allowing a change in positioning, up to that time the worker had to lay on the side of his body (lateral decubitus), now he can be working while sitting; reducing the application of physical force and lowering ergonomic priority to moderate level, as seen in the Suzanne Rodgers' tool in Figure 8.

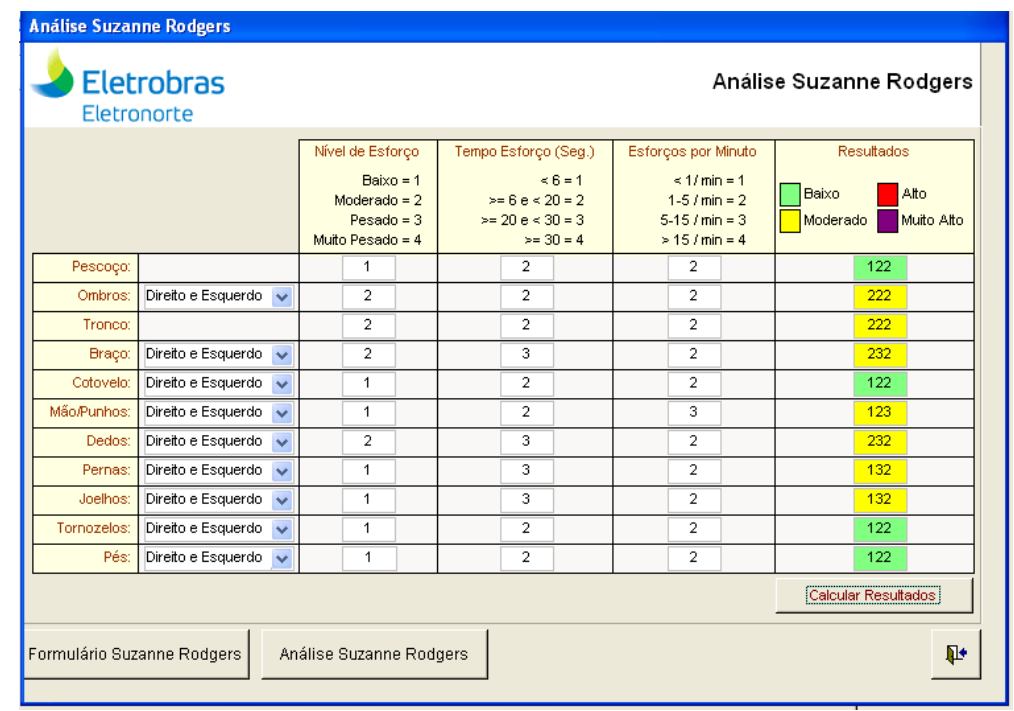

Figure 8 - Suzane Rodger' analysis adapted by Santos - using the device

Table 1 shows the results before and after the implementation of the ergonomic device in Tucuruí. It displays the loss of generation in $\mathrm{MW} / \mathrm{h}$, man*hours used in the execution of the service and the loss of revenue in US\$ (downtime).
Table 1

Results before and after the device development.

\begin{tabular}{|l|c|c|c|}
\hline & BEFORE & AFTER & GOAL \\
\hline $\begin{array}{l}\text { Loss of generation } \\
\text { (downtime) in } \\
\text { MW/h }\end{array}$ & $218,400.00$ & $84,000.00$ & $10,200.00$ \\
\hline $\begin{array}{l}\text { Man*Hour used } \\
\text { in the activity }\end{array}$ & $1,638.00$ & 630.00 & 819.00 \\
\hline $\begin{array}{l}\text { Loss of revenue } \\
\text { in US\$ (down- } \\
\text { time) }\end{array}$ & $1,004,640.00$ & $396,921.00$ & $502,320.00$ \\
\hline
\end{tabular}




\section{Conclusion}

It can be said that the ergonomic improvements contributed significantly for the improvement of the production process as a whole. Results of this work encouraged in other sites within the Tucuruí plant. It was found that investing in ergonomics does not always require a lot of money, adding administrative measures to the ergonomic practices (pauses during maintenance, insertion of an emergency rescue plan, claim for PET - job entry permit (confined space)) resulted in improvements for the health of the employee.

\section{References}

[1] Monchy, F., A Função Manutenção - Formação para a Gerência da Manutenção Industrial, São Paulo, Editora Durban Ltda., 1989.

[2] Nunes, E.L.. Trabalho de dissertação: Manutenção Centrada em Confiabilidade (MCC): Análise da Implantação de Manutenção Preventiva. Florianópolis, 2001.

[3] Nakajima, S. Introdução ao TPM, Tradução de Mario Nishimura, IMC Internacional Sistemas Educativos Ltda, São Paulo, 1989.

[4] Godoy, A.S. (1995) - Pesquisa Qualitativa: Tipos Fundamentais. Revista de Administração de Empresas, v. 35 , n. 3 , p. 25-35.

[5] Bicheno, J. The new Lean toolbox towards fast, flexible flow. Buckingham, England: Picsie Books, 2004

[6] Análise Ergonômica do Trabalho em Empresa de Componentes automotivos. II Encontro Regional de Higiene Ocupacional, 2006. 